\title{
A retrospective analysis of the patterns of failure in pediatric myxopapillary ependymoma
}

\author{
Wan-Yee Teo • Murali Chintagumpala • M. Fatih Okcu • \\ Robert C. Dauser • Anita Mahajan • \\ Adekunle M. Adesina • William E. Whitehead • \\ Andrew Jea • Robert Bollo • Arnold C. Paulino
}

Received: 28 July 2012 / Accepted: 30 August 2012 /Published online: 13 September 2012

(C) Springer-Verlag 2012

\begin{abstract}
Objective Myxopapillary ependymoma (MPE) is a rare tumor, accounting for 10-20\% of pediatric intramedullary spinal cord tumors. Our objective was to study the patterns of dissemination and failure in pediatric MPE.

Methods We performed a retrospective analysis of pediatric patients with MPE seen at our institution, together with a review of children with MPE reported in the PubMed database. A total of 31 pediatric MPE cases were evaluable.

Results Spinal and intracranial dissemination at diagnosis was seen in $13(42 \%)$ and $2(6.5 \%)$ patients, respectively. Three treatment strategies were employed: Group 1: gross total resec-
\end{abstract}

W.-Y. Teo $(\bowtie) \cdot$ M. Chintagumpala $\cdot$ M. F. Okcu • A. C. Paulino Department of Pediatrics, Division of Hematology-Oncology, Texas Children's Cancer Center, Baylor College of Medicine, 1030.11, Feigin Center, 6621 Fannin Street,

Houston, TX 77030, USA

e-mail: wywlzl@singnet.com.sg

R. C. Dauser · A. M. Adesina - W. E. Whitehead • A. Jea • R. Bollo Department of Neurosurgery, Texas Children's Hospital, Baylor College of Medicine,

Houston, TX, USA

M. Chintagumpala $\cdot$ M. F. Okcu $\cdot$ R. C. Dauser $\cdot$ A. M. Adesina W. E. Whitehead $\cdot$ A. Jea $\cdot$ R. Bollo

Dan L. Duncan Cancer Center, Baylor College of Medicine, Houston, TX, USA

\section{A. Mahajan}

Department of Radiation Oncology, MD Anderson Cancer Center, Houston, TX, USA

\section{A. C. Paulino}

Department of Radiation Oncology, Methodist Hospital, Houston, TX, USA tion (GTR) only, $n=12$; Group 2: GTR + radiotherapy (RT), $n=$ 4; and Group 3: subtotal resection + RT, $n=15$. Presence of dissemination at diagnosis in Groups 1, 2, and 3 was 1 (7 \%), 4 (100\%), and 10 (67\%) patients, respectively. Recurrences in Groups 1, 2, and 3 were 6/12 (50\%), 1/4 (25\%), and 3/15 (20\%), respectively. Of all 10 recurrences, eight were successfully salvaged while two progressed, of whom one died. For all 31 patients, local recurrence was more frequent in those who did not receive adjuvant RT (5/12), as compared with patients who received RT $(2 / 19)(p=0.08$, Fisher's exact test).

Conclusions This is the largest comprehensive analysis of patterns of dissemination and failure in pediatric MPE according to the type of treatment. The highest recurrence was seen in children with MPE treated with GTR only. Recurrences were infrequent in Group 3 despite incomplete resection. Salvage treatment was successful in most patients who recurred.

Keywords Myxopapillary ependymoma $\cdot$ Pediatric . Radiation fields $\cdot$ Failure

\section{Introduction}

Myxopapillary ependymoma (MPE) is a rare tumor, accounting for $10-20 \%$ of pediatric intramedullary spinal cord tumors [1-7] and is relatively more common in adults [8-10]. MPE commonly occurs within the conus medullaris and filum terminale $[11,12]$. Histologically, it is classified as WHO grade 1 tumor, demonstrating slow and indolent growth pattern. In adults, it is associated with excellent long-term survival [11]. Unfortunately, reports of pediatric patients with MPE are limited to small series and case reports [1-7, 13]. Most evidence for treatment strategies and recommendations in children with 
MPE have been extrapolated from adult studies [8-10]. Typically, this involves gross total resection (GTR), with radiotherapy (RT) usually reserved for subtotal resection (STR) and recurrent tumors $[1-7,13]$.

There have been recent reports suggesting that pediatric MPE is more aggressive locally and tends to disseminate more frequently compared to its adult counterpart $[1,5,7]$. Therefore, RT could play an important role in the initial management of these tumors. To determine if adjuvant RT may have a role after tumor resection, we performed a retrospective analysis of pediatric patients treated at our institution and patients reported in the PubMed database [1-6], specifically to study the patterns of neuraxis dissemination and failure.

\section{Methods}

Eight patients seen at our institution over a period of 10 years from 1999 to 2009 were identified. We used the PubMed database to identify patients from case series of children with MPE in the published literature. A PubMed search of English language articles from 1997 to 2012 was performed using a combination of the keywords which included myxopapillary ependymoma, children, and pediatric. To be included in the analysis, the following criteria had to be met: presence of MPE in the spinal axis with or without brain involvement, histology-proven MPE, diagnosis between 0 and 18 years of age, and inclusion of treatment information (including dose and field when RT is used). In addition, for all the patients, we compiled data on patient's age at diagnosis, gender, tumor location, presence of dissemination in the spinal axis and/or brain on magnetic resonance imaging (MRI), status at last follow-up, and site of recurrence when applicable. We identified an additional 23 cases of pediatric MPE from six series [1-6] in the PubMed database which satisfied the inclusion criteria. Therefore, 31 patients with pediatric MPE were included in this analysis. Neuraxis dissemination was defined by the non-contiguous extension of tumor beyond the primary site or diffuse central nervous system involvement. Estimates of survival time distributions were performed using the Kaplan-Meier method, SPSS (version 13.0). For overall survival, an event was defined as death.

\section{Results}

\section{Demographics}

The median age of patients at initial diagnosis was 13 years (range, $6-18$ years). About one third (10/31) were $<10$ years of age (Tables 1 and 2). For gender, 20 were males, 10 females,

Table 1 Radiation field and dose in relation to site of recurrence and outcome of pediatric myxopapillary ependymoma from our institution

\begin{tabular}{|c|c|c|c|c|c|c|c|}
\hline $\begin{array}{l}\text { Serial no. } \\
\text { (age, gender) }\end{array}$ & $\begin{array}{l}\text { Original } \\
\text { tumor site }\end{array}$ & Treatment & RT field/dose & $\begin{array}{l}\text { Site of } \\
\text { recurrence }\end{array}$ & $\begin{array}{l}\text { Treatment for } \\
\text { recurrence }\end{array}$ & RT field/dose & Outcome \\
\hline $\begin{array}{l}1 \\
(6, M)\end{array}$ & $\begin{array}{l}\text { T12-L3 } \\
\text { S1-S3 }\end{array}$ & GTR & - & $\begin{array}{l}\mathrm{L} 2-\mathrm{L} 3 \\
\text { Conus }\end{array}$ & RT & $\begin{array}{l}\text { T12-S3 (41.4 CGE) } \\
\text { Boost L1-L3 (9 CGE) }\end{array}$ & $\begin{array}{l}\text { Progression } \\
(2 \text { years })\end{array}$ \\
\hline $\begin{array}{l}2 \\
(8, F)\end{array}$ & $\mathrm{T} 12-\mathrm{S} 3$ & $\mathrm{STR}+\mathrm{RT}$ & $\begin{array}{l}\text { T12-S3 (45 Gy) } \\
\text { Boost L2-S3 ( } 5.4 \text { cGy) }\end{array}$ & $\mathrm{L} 2-\mathrm{S} 3$ & STR & - & $\begin{array}{l}\text { Progression } \\
\text { (4.4 years) }\end{array}$ \\
\hline $\begin{array}{l}3 \\
(13, M)\end{array}$ & $\begin{array}{l}\mathrm{L} 1-\mathrm{S} 2 \\
\mathrm{~T} 11\end{array}$ & $\mathrm{STR}+\mathrm{RT}$ & $\begin{array}{l}\text { T10-S3 (41.4 Gy) } \\
\text { Boost L1-S2 (6.8 Gy) }\end{array}$ & - & - & - & $\begin{array}{l}\text { Stable } \\
(6.8 \text { years })\end{array}$ \\
\hline $\begin{array}{l}4 \\
(14, M)\end{array}$ & $\begin{array}{l}\text { T6 } \\
\text { L2-L3 } \\
\text { L5-S1 }\end{array}$ & $\mathrm{STR}+\mathrm{RT}$ & $\begin{array}{l}\text { T4-S3 (39.6 CGE) } \\
\text { Simultaneous boosts } \\
\text { Boost L2-S2 (14.4 CGE) } \\
\text { Boost T12-L2 (9 CGE) } \\
\text { Boost T6-T7 (9 CGE) }\end{array}$ & - & - & - & $\begin{array}{l}\text { Stable } \\
\text { (1 year) }\end{array}$ \\
\hline $\begin{array}{l}5 \\
(15, M)\end{array}$ & $\begin{array}{l}\text { L1-L3 } \\
\text { S1-S3 }\end{array}$ & $\mathrm{STR}+\mathrm{RT}$ & $\begin{array}{l}\text { T10-S4 (45 CGE) } \\
\text { Sequential boosts } \\
\text { Boost L1-S4 ( } 5.4 \text { CGE) } \\
\text { Boost S1-S4 (3.6 CGE) }\end{array}$ & - & - & - & $\begin{array}{l}\text { Stable } \\
(2.2 \text { years })\end{array}$ \\
\hline $\begin{array}{l}6 \\
(11, M)\end{array}$ & L1-L3 & GTR & - & L1-L3 & RT & Currently receiving RT & $\begin{array}{l}\text { Progression } \\
\text { (4.1 years) }\end{array}$ \\
\hline $\begin{array}{l}7 \\
(18, F)\end{array}$ & L2-L3 & GTR & - & - & - & - & $\begin{array}{l}\text { Stable } \\
(6.1 \text { years })\end{array}$ \\
\hline $\begin{array}{l}8 \\
(18, M)\end{array}$ & L1-L2 & GTR & - & - & - & - & $\begin{array}{l}\text { Stable } \\
(2.2 \text { years })\end{array}$ \\
\hline
\end{tabular}

$M$ male, $F$ female, GTR gross total resection, STR subtotal resection, $R T$ radiotherapy, $C G E$ cobalt gray equivalent 


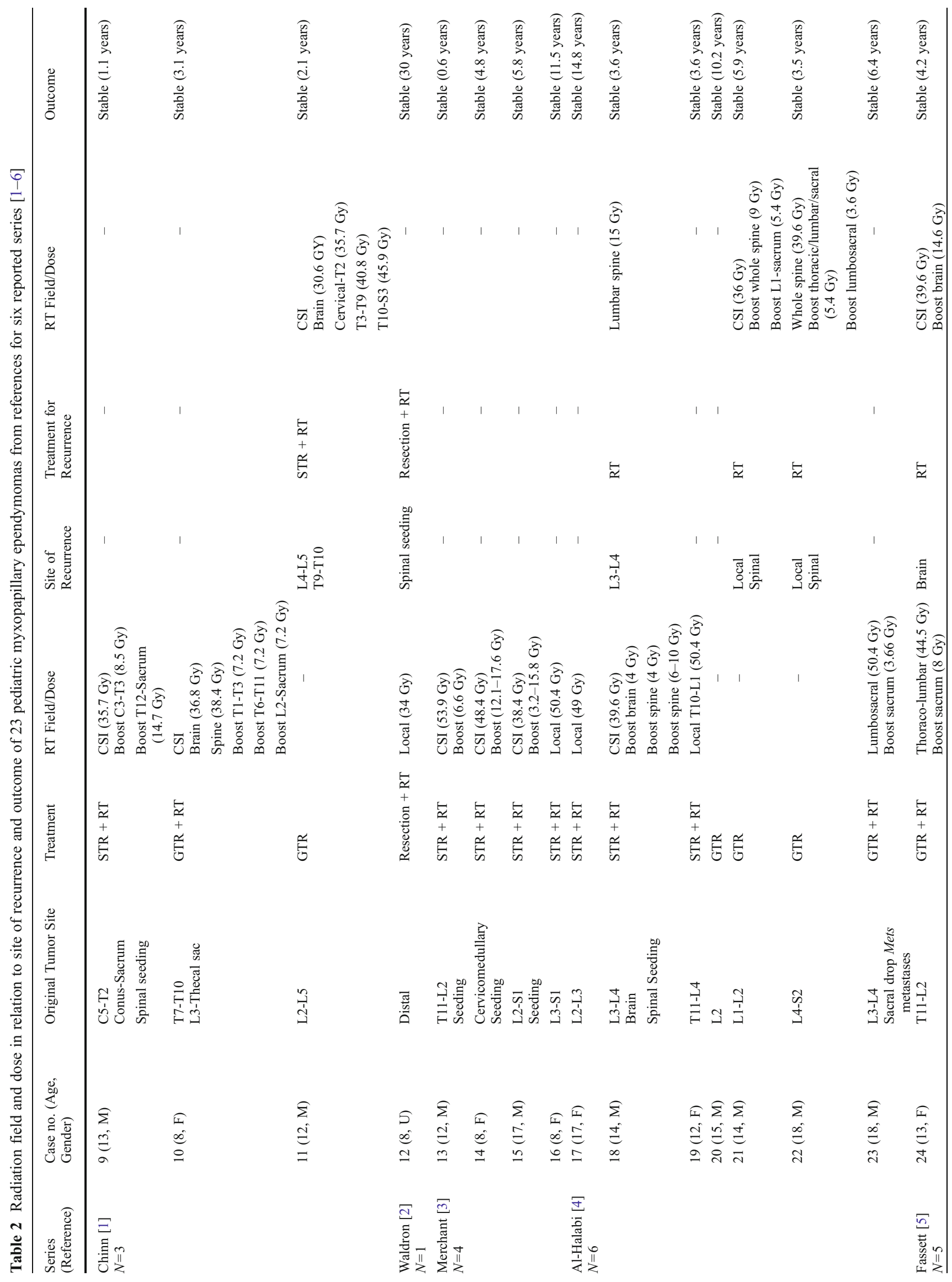




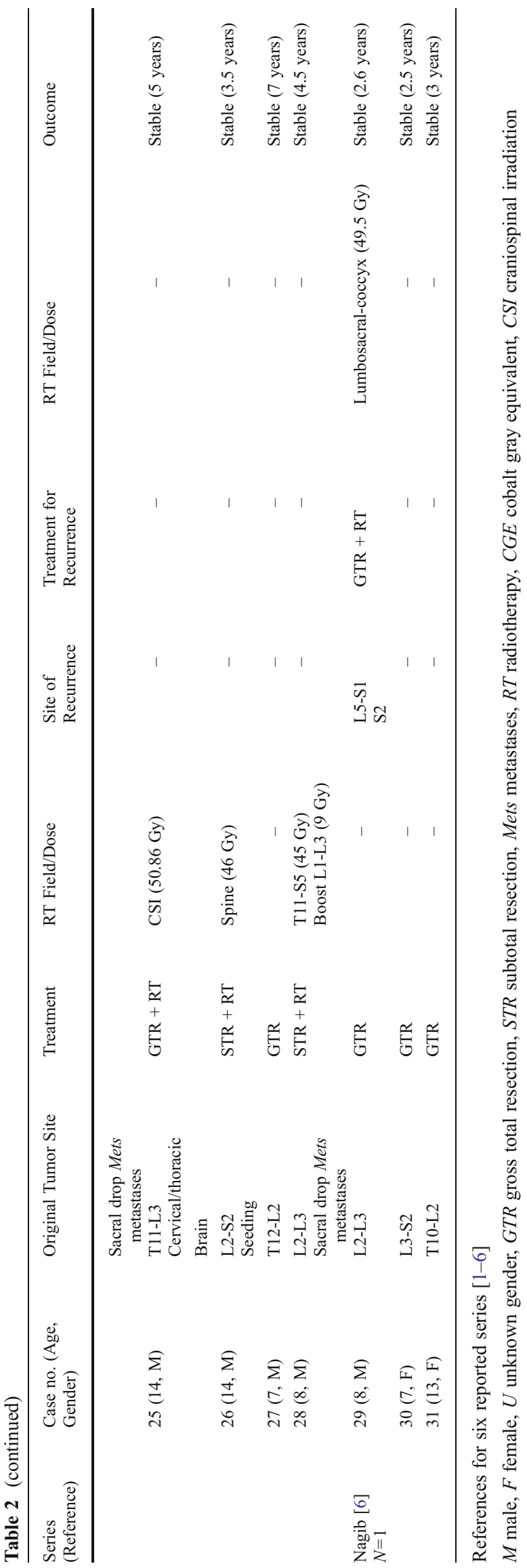

and 1 unknown. All tumors were located in the spinal cord or cauda equina; two patients had intracranial dissemination at diagnosis. Spinal dissemination involving the cervical and thoracic spinal cord was seen in 3 (9.7\%) and 12 (38.7\%) patients, respectively. All the patients had biopsy-proven histology consistent with MPE.

Tumor and treatment characteristics

We classified the treatment strategies into three general groups: Group 1 (GTR only, $n=12$ ), Group 2 (GTR + RT, $n=4)$, and Group 3 (STR $+\mathrm{RT}, n=15)$. Disseminated disease confined to spinal axis at diagnosis was seen in 13 (42\%), and two patients (6.5\%) had intracranial spread. All but one patient with disseminated MPE at diagnosis received adjuvant RT. Seven patients received craniospinal irradiation (CSI) and 12 received involved field radiation, which is defined as a spinal field which encompassed the primary site and areas of dissemination. None of the patients received initial chemotherapy.

Patterns of dissemination and failure according to treatment groups

We further analyzed the patterns of failure among different treatment groups (Table 3). In Group 1, 11 of 12 patients had localized while one patient had disseminated disease confined to the spinal axis at diagnosis. Recurrences were seen in six $(50 \%)$ after GTR, local in one, distant in one, and both local and distant in four. All distant recurrences were confined to the spinal axis. Recurrences were treated with GTR and RT in one (involved spinal field, case 29), STR and CSI in one (case 11), and RT alone in four (two involved spine RT, one whole spine RT, and one CSI in cases 1, 6, 22, and 21 , respectively).

In Group 2, all four cases were disseminated, of which three were confined to the spinal axis and one involved both the spinal cord and brain (case 25). Two patients received involved spinal field RT (cases 23 and 24) and two had CSI (cases 10 and 25). Only one patient (case 24) recurred; this patient had initially received involved spinal field RT and recurrence was distant in the brain. This patient was further treated with CSI and the tumor was stable at 4.2 years from diagnosis.

In Group 3, 10 of 15 patients had dissemination at diagnosis; of which, nine were confined to the spinal axis only and one had concomitant intracranial dissemination (case 18). RT field was CSI in five and involved field in 10 patients. Recurrence was found in 3 of 15 patients $(20 \%)$ treated with adjuvant RT despite incomplete resection. All three recurrences were confined to the spine; two were local (cases 2 and 18) and one was distant (case 12). All three patients with recurrences received further involved spinal field RT. 
Table 3 Patterns of dissemination and failure according to treatment groups $(n=31)$

\begin{tabular}{|c|c|c|c|c|c|c|c|}
\hline Groups & $\begin{array}{l}\text { Treatment } \\
\text { strategy }\end{array}$ & $\begin{array}{l}\text { Total no. of } \\
\text { cases }(n)\end{array}$ & $\begin{array}{l}\text { No. of cases with } \\
\text { dissemination at } \\
\text { diagnosis }\end{array}$ & $\begin{array}{l}\text { No. of cases with } \\
\text { local recurrence }\end{array}$ & $\begin{array}{l}\text { No. of cases with } \\
\text { distant recurrence }\end{array}$ & $\begin{array}{l}\text { No. of cases with } \\
\text { local }+ \text { distant recurrence }\end{array}$ & $\begin{array}{l}\text { Total no. of cases } \\
\text { with recurrences }\end{array}$ \\
\hline Group 1 & GTR only & 12 & 1 & 2 & 0 & 4 & $6(50 \%)$ \\
\hline Group 2 & $\mathrm{GTR}+\mathrm{RT}$ & 4 & 4 & 0 & 1 (brain) & 0 & $1(25 \%)$ \\
\hline Group 3 & $\mathrm{STR}+\mathrm{RT}$ & 15 & 10 & 2 & 0 & 1 & $3(20 \%)$ \\
\hline
\end{tabular}

GTR gross total resection, STR subtotal resection, $R T$ radiotherapy

For all 31 patients, local recurrence was more frequent in those who did not receive adjuvant RT (5/12), as compared with patients who received RT $(2 / 19)$, although not statistically significant (two tailed $p=0.08$, Fisher's exact test). Disseminated disease at diagnosis was more frequent in the group with STR and RT (67\%) compared to the group with GTR without adjuvant RT (7 \%).

Intracranial dissemination

Five of $31(16 \%)$ of the children received CSI in the absence of intracranial dissemination at initial diagnosis. Both patients with initial intracranial dissemination received CSI and subsequently did not recur in the brain. The locations of the intracranial lesions were the brainstem in one patient [5] (case 25) and leptomeninges in the other [4] (case 18). There was only one intracranial relapse, in a patient who initially had disseminated spinal disease and received involved field RT (case 24). The intracranial relapse was in the suprasellar cistern and fourth ventricle [5]. This patient further received craniospinal RT and subsequently remained progression free for 1.2 years.

\section{Outcome}

At a median follow-up of 4.1 years (range, $0.6-30$ years), 28 of 31 patients are alive without progression after initial or salvage therapy. Only one patient died at 4.4 years from diagnosis (case 2). The 10-year overall survival was $92.9 \%$.

\section{Discussion}

This is the largest comprehensive analysis of patterns of dissemination and failure in pediatric MPE. There have been recent reports suggesting that pediatric MPE is more aggressive and tends to disseminate more frequently compared to its adult counterparts $[1,5,7]$. In one study, $21 \%$ of the children and $2.5 \%$ of the adults had dissemination at initial diagnosis [7]. Our analysis demonstrates that the incidence of spinal axis dissemination at diagnosis in pediatric MPE was high at $42 \%$. Pediatric MPE has also been reported with a much higher rate of failure within the neural axis (64\%) compared to adults (32\%), and a shorter time interval to disease recurrence [7]. The overall failure rate in our study was $32 \%$. The patterns of relapse were local (four patients), distant (one patient, in the brain), and both local and distant (five patients).

The patterns of failure suggest that pediatric MPE may benefit from adjuvant RT, regardless of the extent of surgical resection. The highest recurrence was seen in children with MPE treated with GTR only. Local recurrence was more frequent in those who have undergone GTR without adjuvant RT compared with patients with STR followed by RT. This is despite disseminated disease at diagnosis being more frequent in the group with STR and RT (67\%) compared to the group with GTR without adjuvant RT (7\%). Although not statistically significant, likely because of small patient numbers, this information emphasizes the importance of RT in this disease. Although RT after GTR may be useful, it is not clear if upfront RT is necessary after GTR because at relapse, pediatric MPE can be salvaged with RT as seen in 8 of 10 recurrences. In a young child, it may be advantageous to adopt a wait and watch approach and deliver RT at recurrence when the child is older, to avoid neurocognitive effects, musculoskeletal toxicity including height impairment, spinal curvature, muscular hypoplasia, and the risk of secondary malignancy.

We also provide evidence that the incidence of intracranial dissemination in pediatric MPE is low at $6.5 \%$ but higher than in adults. In a large retrospective series of 85 adult patients with MPE, the incidence of intracranial dissemination at initial diagnosis was $1.2 \%(1 / 85)$ [9]. In another adult series of 35 patients, none had intracranial dissemination at initial diagnosis [8]. Based on our findings, we recommend a screening MRI of the brain at diagnosis to rule out intracranial dissemination as it can influence the choice of RT field.

CSI appears to be effective in intracranially disseminated MPE. The role of CSI in the absence of intracranial dissemination is not clear. None of the patients with CSI failed in the brain but whether this is due to CSI effects or the infrequent intracranial dissemination is debatable. 
Furthermore, one third of the patients in our study were less than 10 years of age. This knowledge is crucial particularly in younger children (less than 10 years of age), where omission of cranial RT will spare neurocognitive sequelae of the developing brain. This is less of a concern in adult patients whose brain has achieved full maturity [14-18]. Importantly, $16 \%$ of the children received CSI in the absence of intracranial disease. Our findings suggest that patients who received RT to the spine for initial disseminated spinal disease rarely develop dissemination to the brain. In spite of this, the one patient with intracranial dissemination at recurrence was successfully salvaged with cranial RT.

\section{Conclusion}

Studies on pediatric MPE are limited by small sample sizes because of the rarity of the tumor. Our study has provided information which may be used for management of pediatric MPE. Although pediatric MPE has an excellent long-term outcome, it is more frequently disseminated at initial diagnosis than its adult counterparts. We recommend MRI of the entire neuraxis at initial diagnosis to rule out dissemination. The highest recurrence was seen in children with MPE treated with GTR only, suggesting that RT may have a role after tumor resection; however, this must be individualized according to the expected late toxicities of treatment as these patients can be salvaged with RT at the time of recurrence.

Acknowledgments This work did not involve research funding.

Conflict of interest All the authors declared no conflicts of interest or financial disclosures that are relevant to the subject matter under consideration in this article.

\section{References}

1. Chinn DM, Donaldson SS, Dahl GV et al (2000) Management of children with metastatic spinal myxopapillary ependymoma using craniospinal irradiation. Med Pediatr Oncol 35:443-445

2. Waldron JN, Laperriere NJ, Jaakkimainen et al (1993) Spinal cord ependymomas: a retrospective analysis of 59 cases. Int J Radiat Oncol Biol Phys 27:223-229
3. Merchant TE, Kiehna EN, Thompson SJ et al (2000) Pediatric low grade and ependymal spinal cord tumors. Pediatr Neurosurg 32:30-36

4. Al-Halabi H, Montes JL, Atkinson J et al (2010) Adjuvant radiotherapy in the treatment of pediatric myxopapillary ependymomas. Pediatr Blood Cancer 55:639-643

5. Fassett DR, Pingree J, Kestle JR (2005) The high incidence of tumor dissemination in myxopapillary ependymoma in pediatric patients: report of five cases and review of the literature. J Neurosurg 102:59-64

6. Nagib MG, O'Fallon MT (1997) Myxopapillary ependymoma of the conus medullaris and filum terminale in the pediatric age group. Pediatr Neurosurg 26:2-7

7. Bagley CA, Wilson S, Kothbauer KF et al (2009) Long term outcomes following surgical resection of myxopapillary ependymomas. Neurosurg Rev 32:321-334

8. Akyurek S, Chang EL, Yu TK et al (2006) Spinal myxopapillary ependymoma outcomes in patients treated with surgery and radiotherapy at M.D. Anderson Cancer Center. J Neurooncol $80: 177-183$

9. Pica A, Miller R, Villì S et al (2009) The results of surgery, with or without radiotherapy, for primary spinal myxopapillary ependymoma: a retrospective study from the rare cancer network. Int $\mathrm{J}$ Radiat Oncol Biol Phys 74:1114-1120

10. Chao ST, Kobayashi T, Benzel E et al (2011) The role of adjuvant radiation therapy in the treatment of spinal myxopapillary ependymomas. J Neurosurg Spine 14:59-64

11. Kleihues P, Sobin LH (2000) World Health Organization classification of tumors. Cancer 88:2887

12. Kahan H, Sklar EM, Post MJ et al (1996) MR characteristics of histopathologic subtypes of spinal ependymoma. AmJ Neuroradiol 17:1143-1150

13. Bagley CA, Kothbauer KF, Wilson S et al (2007) Resection of myxopapillary ependymomas in children. J Neurosurg $106(4$ Suppl Pediatrics):261-267

14. Mulhern RK, Horowitz ME, Kovnar EH et al (1989) Neurodevelopmental status of infants and young children treated for brain tumors with preirradiation chemotherapy. J Clin Oncol 7:1660-1666

15. Jenkin D, Danjoux C, Greenberg M (1998) Subsequent quality of life for children irradiated for a brain tumor before age four years. Med Pediatr Oncol 31:506-511

16. Kiltie AE, Lashford LS, Gattamaneni HR (1997) Survival and late effects in medulloblastoma patients treated with craniospinal irradiation under three years old. Med Pediatr Oncol 28:348-354

17. Hoppe-Hirsch E, Brunet L, Laroussinie F et al (1995) Intellectual outcome in children with malignant tumors of the posterior fossa: influence of the field of irradiation and quality of surgery. Childs Nerv Syst 11:340-346

18. Palmer SL, Goloubeva O, Reddick WE et al (2001) Patterns of intellectual development among survivors of pediatric medulloblastoma: a longitudinal analysis. J Clin Oncol 19:2302-2308 